\title{
The Search for New Prognosis Markers for Coronary Artery Disease
}

\author{
Filipe Welson Leal Pereira ${ }^{(0)}$ and Sergio Alberto Rupp de Paiva ${ }^{(1)}$ \\ Departamento de Clínica Médica - Faculdade de Medicina de Botucatu - Universidade Estadual Paulista, Botucatu, SP - Brazil \\ Short Editorial related to the article: Clinical Significance of Platelet Volume and Other Platelet Parameters in Acute Myocardial Infarction and \\ Stable Coronary Artery Disease
}

There is growing evidence that platelets play a key role in vascular atherothrombosis associated with endothelium and inflammation. ${ }^{1}$ Platelet activation leads to abnormalities in the surface glycoprotein expression of these cells, with subsequent aggregation and degranulation, which greatly contribute to thrombus formation. ${ }^{2}$ Corroborating these facts, the role played by antiplatelet agents in the treatment of atherosclerotic vascular disease ${ }^{3}$ is of note. In this context, a study by Ding et al. ${ }^{4}$ shows the association between hematological parameters, with emphasis on leukocyte and platelet indicators, and stable coronary artery disease (SCAD). The authors evaluated platelet count, total platelet mass, mean platelet volume (MPV), platelet amplitude and white blood cell and neutrophil counts of 34 patients diagnosed with SCAD and compared two groups: 50 healthy patients (control) and 31 patients with acute myocardial infarction (AMI). The diagnostic criteria used for SCAD were those established by the European Society of Cardiology guidelines from $2013 .{ }^{4}$ The authors mainly highlighted the association

\section{Keywords}

Acute Coronary Syndrome, Biomarkers; Prognosis; Blood Platelets; Platelet Aggregation.

\section{Mailing Address: Sergio Alberto Rupp de Paiva •}

Faculdade de Medicina de Botucatu - UNESP - Campus de Botucatu - Av. Prof. Mário Rubens Guimarães Montenegro, s/n. Postal Code 18618-687, Botucatu, SP - Brazil

E-mail: sergio.paiva@unesp.br

DOI: 10.5935/abc.20190098 between higher values of MPV and the presence of SCAD compared with the control group. ${ }^{4}$

Some previous studies have outlined the relationship between MPV and the presence of cardiovascular risk factors or acute myocardial infarction. ${ }^{5,6}$ The findings are not always consistent. In a systematic review of 2010, evaluating 16 cross-sectional studies, 14 presented a positive association between higher MPV values in patients with AMI compared with groups without AMI. ${ }^{7}$ The association between high platelet volume value and coronary artery disease (CAD) was also shown in another meta-analysis on this matter in 2014. In this last systematic review, the authors found that patients with MPV values greater than 7.3 were more likely to present CAD than those with lower values. ${ }^{8}$ On the other hand, Wada et al. ${ }^{9}$ found an association between lower MPV values and the presence of stable CAD. ${ }^{9}$

Another reason for discussion among the researchers is the use of MPV as a parameter of platelet function, as MPV is not associated with platelet aggregation by turbidimetry. This latter method is considered a gold standard for evaluating platelet aggregation. ${ }^{10}$

The pursuit for new risk markers and prognosis for coronary disease is ongoing. In this context, MPV can be added to highsensitivity C-reactive protein, to coronary calcium score and to the carotid intima-media thickness. However, in different countries, MPV may be a measure with a better profile, since it is inexpensive, technically easy and little invasive. ${ }^{9}$ The new study by Ding et al. ${ }^{4}$ adds more data to assist in the choice of MPV as a prognostic method in one of the CAD categories.

\section{References}

1. Hamilos M, Petousis S, Parthenakis F. Interaction between platelets and endothelium: from pathophysiology to new therapeutic options. Cardiovasc Diagn Ther. 2018;8(5):568-80.

2. Gaiz A, Mosawy S, Colson N, Singh I. Thrombotic and cardiovascular risks in type two diabetes; Role of platelet hyperactivity. Biomed Pharmacother. 2017 Oct;94:679-86.

3. Smith TJ, Johnson JL, Habtewold A, Burmeister MA. Cardiovascular risk reduction: a pharmacotherapeutic update for antiplatelet medications. Crit Care Nurs Clin North Am. 2019;31(1):15-30.

4. Ding L, Sun L, Wang F, Zhu L, Zhang T, Hua F. Clinical significance of platelet volume and other platelet parameters in acute myocardial infarction and stable coronary artery disease. Arq Bras Cardiol. 2019; 112(6):715-719.

5. Sansanayudh N, Muntham D, Yamwong S, Sritara P, Akrawichien T, Thakkinstian A. The association between mean platelet volume and cardiovascular risk factors. Eur J Intern Med. 2016 May; 30:37-42.
6. Ranjith MP, DivyaRaj R, Mathew D, George B, Krishnan MN. Mean platelet volume and cardiovascular outcomes in acute myocardial infarction. Heart Asia. 2016;8(1):16-20.

7. Chu SG, Becker RC, Berger PB, Bhatt DL, Eikelboom JW, Konkle B, et al Mean platelet volume as a predictor of cardiovascular risk: a systematic review and meta-analysis. J Thromb Haemost. 2010;8(1):148-56.

8. Sansanayudh N, Anothaisintawee T, Muntham D, McEvoy M, Attia J, Thakkinstian A. Mean platelet volume and coronary artery disease: a systematic review and meta-analysis. Int J Cardiol. 2014;175(3):433-40.

9. Wada H, Dohi T, Miyauchi K, Shitara J, Endo H, Doi S, et al. Mean platelet volume and long-term cardiovascular outcomes in patients with stable coronary artery disease. Atherosclerosis. 2018 Oct;277:108-12.

10. Sansanayudh N, Thakkinstian A. Author's reply: mean platelet volume and cardiovascular risk factors. Eur J Intern Med. 2016 Jun;31:e16-7. 